\title{
POU class 1 homeobox 1 gene polymorphisms associated with growth traits in Korean native chicken
}

\author{
Prabuddha Manjula ${ }^{1}$, Nuri Choi ${ }^{1}$, Dongwon Seo ${ }^{1}$, and Jun Heon Lee ${ }^{1, *}$
}

* Corresponding Author: Jun Heon Lee Tel: +82-42-821-5779, Fax: +82-42-825-9754,

E-mail: junheon@cnu.ac.kr

1 Division of Animal and Dairy Science, Chungnam National University, Daejeon 34134, Korea

\section{ORCID}

Prabuddha Manjula

https://orcid.org/0000-0001-8074-8323

Nuri Choi

https://orcid.org/0000-0002-5526-5124

Dongwon Seo

https://orcid.org/0000-0003-0548-7068

Jun Heon Lee

https://orcid.org/0000-0003-3996-9209

Submitted May 9, 2017; Revised Aug 2, 2017; Accepted Sept 11, 2017
Objective: POU class 1 homeobox 1 (POU1F1) mediates growth hormone expression and activity by altering transcription, eventually resulting in growth rate variations. Therefore, we aimed to identify chicken $P O U 1 F 1$ polymorphisms and evaluate the association between single nucleotide polymorphisms (SNPs) and growth-related traits, and logistic growth curve parameter traits $(\alpha, \beta$, and $\gamma)$.

Methods: Three SNPs ( $M \_1$ to $M \_3$ ) were used to genotype $585 \mathrm{~F}_{1}$ and $88 \mathrm{~F}_{0}$ birds from five Korean native chicken lines using a polymerase chain reaction-restriction fragment length polymorphism method.

Results: Single marker analyses and traits association analyses showed that $M \_2$ was significantly associated with body weight at two weeks, weight gain from hatch to 2 weeks, and weight gain from 16 to 18 weeks $(\mathrm{p}<0.05)$. M_3 was significantly associated with weight gain from 14 to 16 weeks and from 16 to 18 weeks, and asymptotic body weight $(\alpha)(p<0.05)$. No traits were associated with $M \_1$. The POU1F1 haplogroups were significantly associated with weight gain from 14 to 16 weeks $(\mathrm{p}=0.020)$. Linkage disequilibrium test and Haploview analysis shown one main haploblock between $M \_2$ and $M \_3$ SNP.

Conclusion: Thus, $P O U 1 F 1$ significantly affects the growth of Korean native chickens and their growth curve traits.

Keywords: Growth Traits; Korean Native Chicken; POU1F1 Gene; Association

\section{INTRODUCTION}

Recently, rare and heritage animal breeds and their genetic resources have become more important as they offer economically viable and distinct meat quality characteristics. One such example is the Korean Native Chicken (KNC) that is growing in popularity with consumers because of its unique meat qualities. However, native chicken lines tend to have lower growth rates and production performances than commercial breeds. Improving growth rate and production performance in $\mathrm{KNC}$ breeds is an increasingly important issue for the Korean chicken industry.

Traditional quantitative genetics approaches cannot discriminate among the effects of sets of genes associated with variations in quantitative traits. However, the recent developments in molecular biology technologies, such as quantitative trait locus analysis and candidate gene approaches have provided better tools for identifying functional genes, and for applying the obtained knowledge in breeding programs to improve economically important traits in animals [1]. Information on functional genes helps the selection of animals with favourable breeding traits and increases the efficiency of selecting for improvements in growth rates, body weights, and carcass traits [2].

POU class 1 homeobox 1 (POU1F1) gene is considered as a strong candidate among genes 
affecting variation in animal growth rates. POU1F1 has a POUdomain binding domain and can trans-activate the promotor region of growth hormone $(G H)$, prolactin $(P R L)$, thyroid stimulating hormone chain $(T B S H)$ encoding genes and POU1F1 itself in the anterior pituitary [3].

POU1F1 is a tissue specific transcription factor that regulates gene expression, particularly in somatotrophs, lactotrophs, and thyrotrophs, which are responsible for growth related hormone secretion [4]. The cDNA sequence of chicken POU1F1 has been identified [5]. According to the chicken genome assembly Gallus_gallus-5.0 (Gene ID: 374215), POU1F1 is located on chromosome 1 and is $14 \mathrm{~kb}$ long. Single nucleotide polymorphisms (SNPs) in POU1F1 have been identified in swine, bovine and chickens and their associations with growth, meat quality, and fatty acid profile have been analyzed [1,6-8]. A non-synonyms SNP (A>T, Asn229Ile) was identified in the POU domain and showed significant association with body weight in 8-week-old chickens [6]. Similarly, Nie et al [9] reported four SNPs and a $57 \mathrm{bp}$ indel polymorphism that were significantly associated with early growth and body weight of a Chinese breed of chicken. Mutation of chicken POU1F1 may control the expression and activity of growth hormones by altering transcription rates; these alterations eventually result in growth variations. Given the pivotal role of these hormones in growth, $P O U 1 F 1$ can be considered as a vital candidate gene for production traits in chicken. In this light, the objective of this study was to identify SNPs in POU1F1 and evaluate their associations with growth related traits (body weight [BW], weight gain [GR], and growth curve parameter traits) in the KNC.

\section{MATERIALS AND METHODS}

\section{Animal care}

All practices and procedures in this study strictly followed "The Guide for Care and Use of Laboratory Animals" published by the Institutional Animal Care and Use Committee of the National Institute of Animal Science (NIAS) (2012-C-037) in Korea.

\section{Chicken population}

The chicken population described in previous studies was used [10-12]. It consisted of five $\mathrm{F}_{1}$ lines of KNCs: Black line (88 chickens), Grey line (111 chickens), Red line (135 chickens), White line (121 chickens), and Yellow line (130 chickens), and the parents $\left(\mathrm{F}_{0}, 88\right.$ chickens). All the birds were nurtured under the standard feeding and environmental conditions of the National Institute of Animal Science (NIAS) Korea. Phenotypes were measured during the experiment period as part of the breeding program. The body weight of each individual was measured at two-week intervals from hatching to 20-weekold and used to calculate the weight gain in two-week intervals.
The longitudinal body weight data were fitted to a logistic growth model $\left(W_{(t)}=\alpha /\left[1+\beta e^{-\gamma t}\right]\right)$ to obtain three growth curve parameters: $\alpha=$ asymptotic body weight; $\beta=$ the log-function for the proportion of the asymptotic mature weight to be gain after birth (week); $\gamma=$ scale proportional to the overall growth rate. For the molecular analysis, blood samples were collected in ethylene diamine tetra acetic acid containing tubes and were provided by NIAS Korea. Genomic DNAs were isolated according to the published method [13]. The purity and concentration of the DNAs were assessed by spectrophotometry method (NANODrop 2000, Thermo Scientific, Wilmington, DE, USA). Stock DNAs were diluted with ultrapure water to produce a working concentration of $25 \mathrm{ng} / \mu \mathrm{L}$ and stored at $-20^{\circ} \mathrm{C}$ until use.

\section{Genotyping of SNPs in POU1F1}

Three SNP polymorphisms of chicken POU1F1 gene were genotype by polymerase chain reaction-restriction fragment length polymorphism (PCR-RFLP) method. SNPs were named as $M \_1$ to $M \_3$. The $M \_1$ SNP is a mutation at g. $6758 \mathrm{~T}>\mathrm{C}$ in exon 5 of $P O U 1 F 1$ and not reported previously. The SNP $M \_2$ (g. 9432T>C) and $M \_3$ (g.11041T>C) were referred to gene bank accession number: rs13687127, rs13687128, respectively and were previously reported in chicken [9] (Table 1). All the Three SNPs were first screened to confirm by using the next generation sequence data of KNCs parents' population. Three pairs of PCR primers were designed based upon the chicken POU1F1 gene sequences using Primer 3.0 software (Table 1). PCR was performed to amplify sequence fragments of the markers (Thermal cycler T100, Bio-Rad, Hercules, CA, USA) in exons 5, 6, and intron 5 of POU1F1 gene. The PCR mixture $(20 \mu \mathrm{L})$ contained $50 \mathrm{ng} / \mu \mathrm{L}$ of chicken genomic DNA, Prime PCR buffer (Genetbio Inc., Daejeon, Korea), 1.6 $\mu \mathrm{L}$ dNTPs, 0.2 U Taq DNA polymerase (Genetbio Inc., Korea), 0.8 pmol of each forward and reverse primer $\left(M \_1\right.$ to $\left.M \_3\right)$, and distilled water. PCR was performed using the following PCR thermal cycler conditions. Initial denaturation at $94^{\circ} \mathrm{C}$ for $10 \mathrm{~min}$; 34 to $35 \mathrm{cycles}$ of $94^{\circ} \mathrm{C}$ for $30 \mathrm{~s}$, specific annealing temperature for each marker $\left(60^{\circ} \mathrm{C}\right.$ to $\left.67^{\circ} \mathrm{C}\right)$ for $30 \mathrm{~s}$, and $72^{\circ} \mathrm{C}$ for $30 \mathrm{~s}$; and final extension at $72^{\circ} \mathrm{C}$ for $10 \mathrm{~min}$. The PCR products were digested at $37^{\circ} \mathrm{C}$ for 6 to $12 \mathrm{~h}$ with $H h a \mathrm{I}, E c o \mathrm{RI}$, or $B s p H I$ (Table 1). The digestion mixture $(20 \mu \mathrm{L})$ contained 15 $\mu \mathrm{L}$ PCR product, $1 \times$ digestion buffer, two units of each enzyme and distilled water. Genotypes of $M \_1$ to $M \_3$ were determined using an ultraviolet trans illuminator after 3.0\% agarose gel electrophoresis of the digestion mixture at $120 \mathrm{~V}$ for 30 minutes.

\section{Statistical analysis}

Genotype and allele frequencies were calculated by the direct counting method [14]. Hardy-Weinberg equilibriums for KNC population was analysed using Chi Square $\left(x^{2}\right)$ tests with a significance level of $\mathrm{p}<0.05$, using the 'Hardy-Weinberg' 
Table 1. PCR-RFLP primers and restriction enzymes used to identify POU1F1 gene polymorphisms

\begin{tabular}{|c|c|c|c|c|c|}
\hline Marker name & Location $^{1)}$ & Region & Primer (Forward/Reverse) (5'-3') & Restriction enzyme & Amplicon (bp) \\
\hline M_1 & g.6758T $>C$ & Exon 5 & $\begin{array}{l}\text { AGTATAGCTCTGTGGTGCAC } \\
\text { TATGCCCTCAGATGTCCCAG }\end{array}$ & Hhal & 626 \\
\hline M_2 & g. $9432 \mathrm{~T}>\mathrm{C}$ & Intron 5 & $\begin{array}{l}\text { GGGGATTTTGCCACTTTAGGG } \\
\text { TGGGTAAGGCTCTGGCACTGT }\end{array}$ & EcoRl & 442 \\
\hline M_3 & g. $11041 \mathrm{~T}>\mathrm{C}$ & Exon 6 & $\begin{array}{l}\text { GGGGTACCACTCAACTTCAG } \\
\text { TAGGGTACCTGCAATGGGGG }\end{array}$ & BspHI & 750 \\
\hline
\end{tabular}

PCR-RFLP, polymerase chain reaction-restriction fragment length polymorphism; POU1F1, POU class 1 homeobox 1.

1) Nucleotide positions are numbered according to the first base of gene as it appears in GenBank. $M \_2$ and $M \_3$ were refer to NCBI accession number of rs 13687127, and rs 13687128, respectively. M_1 marker identified in Korean Native Chickens.

package in $\mathrm{R}$ version 3.2.5 [15]. Based on the allele distribution results, all the lines were pooled. Single SNP marker association analyses were performed with the general linear model procedure of analysis of variance in Minitab version 15 [16]. Haplotype inferences and haplotype frequencies were obtained using Phase 2.1 software [17] and the Haploview program [18]. Associations between haplogroups and traits were calculated using same statistical model by replacing Genotype $\mathrm{e}_{\mathrm{i}}$

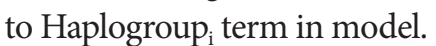

Linear mixed model analysis was performed using following mathematical model;

$$
\begin{aligned}
\mathrm{Y}_{\mathrm{ijklmnn}}= & \mu+\text { Genotype }_{i}+\text { Sex }_{j}+\text { Batch }_{k} \\
& + \text { Line }_{l}+\text { Sire }_{m(\text { (line) }}+\text { Dam }_{n(\text { (inesire) }}+e_{i j k l m n o}
\end{aligned}
$$

Where, $Y_{i j k l m n n}$ is the response of each growth trait, $\mu$ is the overall mean, $\operatorname{Sex}_{j}$ is the fixed effect of the $i^{\text {th }}$ sex ( $\mathrm{i}=$ male, female), Batch ${ }_{k}$ is the fixed effect of the $k_{t h}$ batch $(\mathrm{k}=1,2)$, Line $_{l}$ is the fixed effect of the $l^{\text {th }}$ line $(l=1,2,3,4,5)$, Sire $_{\text {m(line) }}$ is the effect of the $m^{\text {th }}$ sire nested in the $l^{\text {th }}$ line, Dam $m_{n(\text { linesire }}$ is the effect of the $n^{\text {th }}$ dam nested in the $t^{\text {th }}$ line and $m^{\text {th }}$ sire, and $e_{i j k l m n o}$ is the random residual effect. The level of significance for an association was taken and pairwise comparisons between genotypes were obtained using Tukey's test at $\mathrm{p}$ value $<0.05$. Regression analyses of traits and SNPs were performed to obtain regression coefficients for dominance and additive effects [14]. To calculate the dominance and additive effects of each SNP, "genotype effect" in the model was replaced by dominance effect $\left(\mathrm{X}_{\mathrm{dom}}\right)$, (genotypes were coded as 0-1-0 for CC, $\mathrm{CT}, \mathrm{TT}$, respectively) and additive effect $\left(\mathrm{X}_{\mathrm{add}}\right)$ (coded as 0,1 , for two homozygous and 2 for heterozygous based on the minor allele frequency) [19].

\section{RESULTS}

Genotypes and haplotype inference

In this study, we describe three SNPs (M_1 to $M \_3$ ) in the KNC (Figure 1); two of these SNPs have previously been identified in the reciprocal crosses of white recessive rock male and Chinese Xinghua female chicken breed [9]. Digestion of PCR fragment of the $M \_1$ SNP in exon 5 with HhaI, produced fragments lengths of $626 \mathrm{bp}$ for the TT genotype, and $417 \mathrm{bp}$ and $209 \mathrm{bp}$ for the CC genotype and 626,417,209 for CT genotype. The CC, CT, and TT genotype frequencies of $M \_1$ were 0.86 , 0.10 , and 0.04 , respectively. The corresponding $\mathrm{C}$ and $\mathrm{T}$ allele frequencies were 0.91 and 0.09 , respectively. The $M \_2$ SNP in intron 5 (genebank accession number rs13687127) PCR product was digested with $E c o R 1$, produced a $442 \mathrm{bp}$ fragment for the CC homozygote, 246 and $196 \mathrm{bp}$ fragments were in the TT homozygote and 442, 246, and 196 bp in heterozygous CT genotype. The frequency of the CC genotype was 0.87 while the frequency of the CT and TT genotypes were 0.11 and 0.022 , respectively. PCR product of $M \_3$ SNP (genebank accession number rs13687128) produced fragments of 283, 251, and $216 \mathrm{bp}$ for CC the genotype and $467 \mathrm{bp}$ and $283 \mathrm{bp}$ for the TT genotype and 467,283,251, and 216 bp for heterozygous CT genotype after digest with BspH1. In M_3 SNP, CC genotype was most frequent (0.83) and the TT genotype was least frequent (0.03); the CT genotype also occurred at a low frequency value of 0.14 .

Genotypes and allele frequencies for all markers $\left(M \_1\right.$ to $\left.M \_3\right)$ and Chi Square $\left(x^{2}\right)$ tests for Hardy-Weinberg equilibrium were calculated and are summarized in Table 2. The CC genotype was more frequently observed in $\mathrm{KNC}$ than in other genotypes, and the $\mathrm{C}$ allele frequency was higher than that of the T allele in all SNPs. None of the SNPs was in HardyWeinberg equilibrium in $\mathrm{KNC}$ population.

Four haplotypes were reported in this study. Among these, CCC (H1) was the major haplotype $(88.01 \%, 1,029 / 1168)$, three minor haplotypes were also found at frequencies of lower than 1\%: CTT, TCC, TTT (H4 (32/1,168), (H5 49/1,168), and $\mathrm{H6}(58 / 1,168)$, respectively).

Log of the likelihood odds ratio scores (LOD), a pairwise measure of linkage disequilibrium $\mathrm{D}^{\prime}=|\mathrm{D}| / \mathrm{D}_{\max }$ [20] between the three SNP loci were estimated. Higher $\mathrm{D}^{\prime}$ indicates a low recombination rate between the loci. The $\mathrm{D}^{\prime}, \mathrm{LOD}$, and regression coefficient $\left(r^{2}\right)$ values between $M \_1$ and $M \_2$ were $0.596,36.83 \%$, and 0.294 , respectively; between $M \_1$ and $M \_3$, they were $0.563,32.63 \%$, and 0.314 , respectively. The highest $\mathrm{D}^{\prime}$ and $r^{2}$ values were found between $M \_2$ and $M \_3$ and were 
(a)
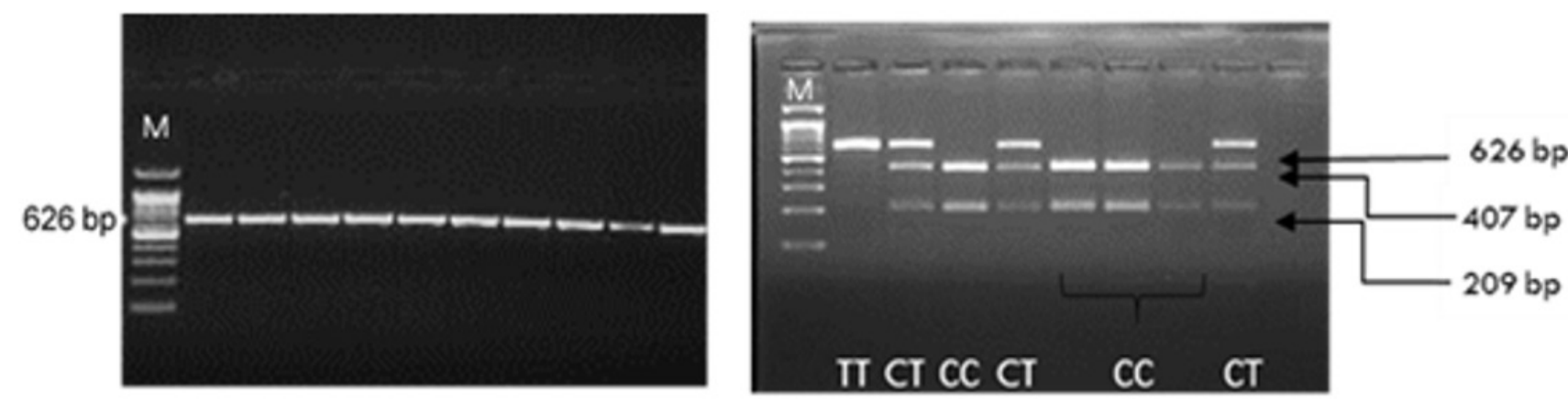

(b)
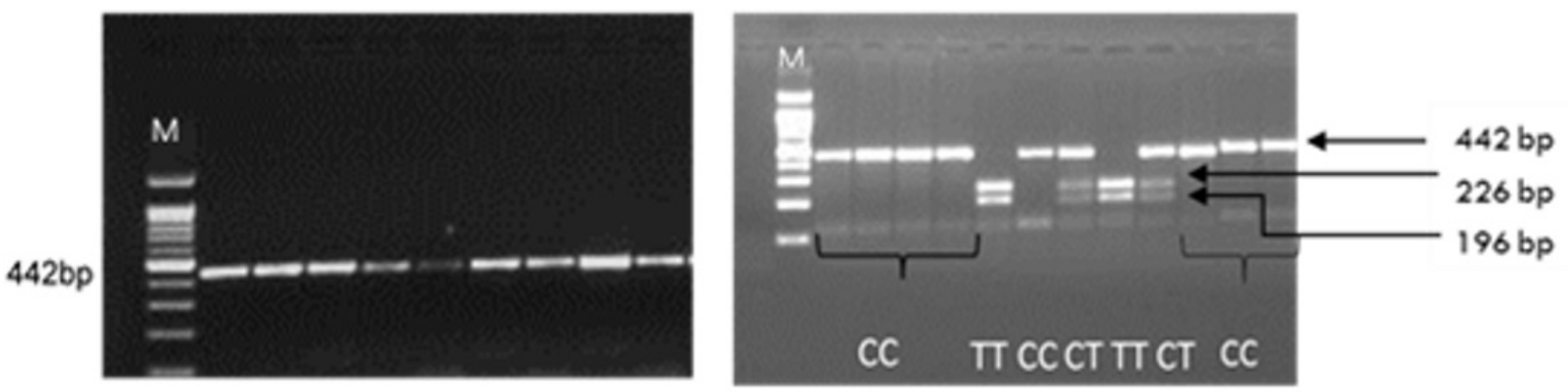

(c)
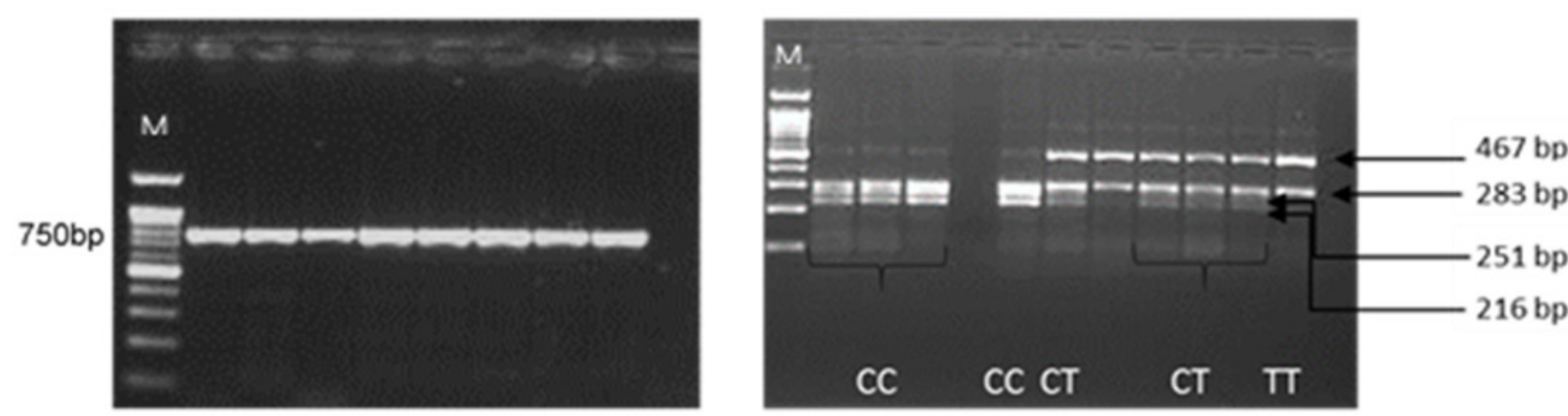

Figure 1. PCR-RFLP patterns for the SNPs in POU1F1. (a) Genotypes of M_1 (g.6758T>C) digested with Hhal, (b) genotypes of M_2 (g.9432T>C) digested with EcoR1, (c) genotypes of $M_{-} 3$ (g.11041T>C) digested with BspH1. PCR-RFLP, polymerase chain reaction-restriction fragment length polymorphism; SNP, single nucleotide polymorphism; POUIF1, POU class 1 homeobox 1.

Table 2. Genotype and gene frequency of POU1F1 SNP polymorphisms in Korean native chickens ${ }^{1)}$

\begin{tabular}{|c|c|c|c|c|c|c|c|}
\hline \multirow{2}{*}{ Item } & \multicolumn{3}{|c|}{ Genotype frequency } & \multicolumn{2}{|c|}{ Allele frequency } & \multicolumn{2}{|c|}{$\chi^{2}$ test $^{2)}$} \\
\hline & $\mathrm{CC}$ & $\mathrm{CT}$ & TT & $\mathrm{C}$ & $T$ & $\chi^{2}$ & $p<0.005$ \\
\hline M_1 & 0.858 & 0.101 & 0.041 & 0.908 & 0.092 & 85.92 & 0.000 \\
\hline M_3 & 0.844 & 0.130 & 0.026 & 0.909 & 0.091 & 23.82 & $1.059 \mathrm{e}-06$ \\
\hline
\end{tabular}

POU1F1, POU class 1 homeobox 1; SNP, single nucleotide polymorphism.

1) SNP position in POU1F1 gene, based on gene counting method genotypes and allele frequency for SNPs were shown in each row.

${ }^{2)}$ Chi Square test for Hardy-Weinberg equilibrium for each SNP in the sampled population. 


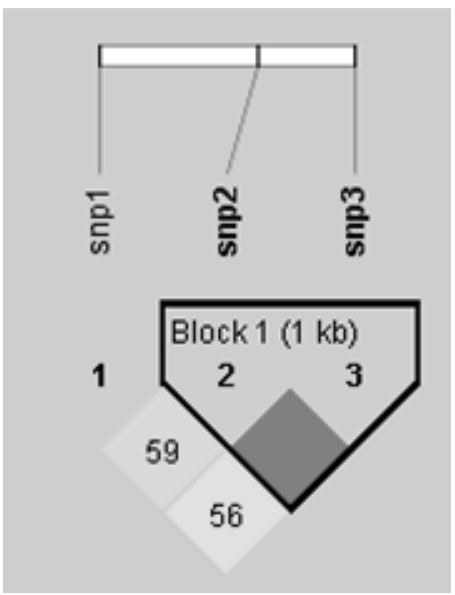

Figure 2. Linkage disequilibrium (LD) in the POU1F1 SNP haplotype block. Haplotype frequency and pairwise measures of $L D\left(D^{\prime}\right)$, which represent the degree of LD between two blocks, are shown for Korean native chickens. Observation of $D^{\prime}$ values indicate one main haplotype block covering the SNP2 to SNP3 region in POU1F1 gene (SNP1, g.6,758T>C; SNP2, g.9,432C > ; SNP3, g.11,041C>T). POU1F1, POU class 1 homeobox 1; SNP, single nucleotide polymorphism.

0.999 , and 0.836 , respectively (Figure 2 ).

\section{Association of SNPs with growth traits}

A single marker trait analysis showed that $M \_1$ SNP was not significantly associated with any of the growth traits tested in KNC. Whereas, $M \_2$ SNP was significantly associated with body weight at two weeks (BW02), weight gain from hatch to two weeks (GR0-2), weight gain from 16 to 18 weeks (GR1618) $(\mathrm{p}<0.05)$, and with asymptotic body weight $(\alpha)(\mathrm{p}<0.1)$ (Table 3). The highest BW02 and GR0-2 were found in the TT type animals, while the lowest was observed in the CT type. However, for weight gain, GR16-18, the CC animals had a higher weight gain than the TT animals, while the CT type showed moderate weight gain. The M_3 SNP was significantly associated with weight gain from 14 to 16 weeks (GR14-16), weight gain from 16 to 18 weeks (GR16-18), and with asymptotic body weight $(\alpha)(p<0.05)$. The CC type had the highest weight gain and asymptotic body weight $(\alpha)$, while TT type had the lowest values. Overall, GR14-16, GR16-18, and $\alpha$ trait in the CC animals were significantly different from those in the TT animals by $19 \%, 25 \%$, and $1.1 \%$, respectively (Table 3 ).

\section{Association between haplotypes and growth traits}

We screened the haplotypes of the 584 individuals in this study and found four haplotypes and eight diploids: $\mathrm{H} 1 \mathrm{H} 1$ (482), H1H2 (14), HIH3 (14), H1H4 (37), H2H2 (5), H2H4 (8), $\mathrm{H} 3 \mathrm{H} 3$ (11), $\mathrm{H} 3 \mathrm{H} 4$ (13). The haplogroup $\mathrm{H} 1 \mathrm{H} 3$ was associated with GR14-16 and had higher weight gain than those of the $\mathrm{H} 1 \mathrm{H} 4$ and $\mathrm{H} 2 \mathrm{H} 2$ (Supplementary Table S3).

\section{DISCUSSION}

This study was initiated to identify polymorphisms in the chicken POU1F1 gene that were related to growth, growth curve parameters, and weight gain traits in KNC. Previous studies have examined POU1F1 of domestic animals and identified its polymorphisms associated with growth traits $[8,21]$. Among the SNPs reported to be associated with growth related traits in chickens, most had significant effects $[6,9,22]$.

Variability in allele frequencies among populations indicates genetic differences in their base population [23]. The genotype frequencies for all three SNPs in our study did not conform to the Hardy-Weinberg equilibrium. Especially, in line G, W, and Y only observed homozygous CC allele type for all SNP. While $\mathrm{R}$ and $\mathrm{L}$ lines were consisted all the three gen-

Table 3. Association of POU1F1 polymorphisms and growth traits (least square means)

\begin{tabular}{|c|c|c|c|c|c|c|}
\hline \multirow{2}{*}{ Trait $^{1)}$} & \multicolumn{3}{|c|}{ Genotype of $M \_2$} & \multirow{2}{*}{ p-value } & \multicolumn{2}{|c|}{ Effect } \\
\hline & $\mathrm{CC}(507)$ & $\mathrm{CT}(64)$ & $\mathrm{TT}(13)$ & & Additive & Dominance \\
\hline BW02 (g) & $142.41 \pm 1.13^{\mathrm{a}}$ & $134.70 \pm 2.27^{b}$ & $143.68 \pm 4.42^{\mathrm{a}}$ & 0.032 & 7.89 & -8.345 \\
\hline GRO-2 (g) & $103.66 \pm 1.07^{\mathrm{a}}$ & $96.59 \pm 2.64^{b}$ & $106.37 \pm 3.60^{\mathrm{a}}$ & 0.008 & 2.73 & -8.425 \\
\hline GR16-18 (g) & $218.04 \pm 5.10^{a}$ & $178.95 \pm 24.0^{b}$ & $148.56 \pm 22.3^{b}$ & 0.016 & -28.80 & -0.042 \\
\hline \multirow[t]{3}{*}{$\alpha(g)$} & $7.679 \pm 0.018$ & $7.598 \pm 0.077$ & $7.598 \pm 0.077$ & \multirow[t]{3}{*}{0.062} & \multirow[t]{3}{*}{-} & \multirow[t]{3}{*}{-} \\
\hline & & jenotype of $M \_3$ & & & & \\
\hline & CC(493) & $\mathrm{CT}(76)$ & $\mathrm{TT}(15)$ & & & \\
\hline GRO-2 (g) & $103.48 \pm 1.07$ & $98.52 \pm 2.67$ & $105.21 \pm 4.30$ & 0.081 & - & - \\
\hline GR14-16 (g) & $217.93 \pm 3.53^{\mathrm{a}}$ & $182.78 \pm 8.51^{\mathrm{ab}}$ & $174.57 \pm 17.8^{b}$ & 0.043 & -11.95 & -13.47 \\
\hline GR16-18 (g) & $217.93 \pm 5.10^{b}$ & $185.32 \pm 224.70^{b}$ & $162.97 \pm 20.50^{\mathrm{a}}$ & 0.040 & -24.95 & -5.13 \\
\hline$\gamma(w k)$ & $0.228 \pm 0.001$ & $0.239 \pm 0.003$ & $0.228 \pm 0.006$ & 0.066 & - & - \\
\hline$\alpha(g)$ & $7.684 \pm 0.018^{\mathrm{ab}}$ & $7.599 \pm 0.36^{b}$ & $7.598 \pm 0.077^{b}$ & 0.030 & -0.095 & -0.04 \\
\hline
\end{tabular}

POU1F1, POU class 1 homeobox 1.

1) BW, body weight at 2 weeks; GRO-2, weight gain from 0 to 2 weeks; GR14-16, weight gain from 14 to 16 weeks; GR16-18, weight gain from 16 to 18 weeks; $\alpha$, asymptotic final body weight $(\mathrm{g}) ; \gamma$, constant scale that is proportional to the overall growth rate (Numbers in bracket refer to sample size for each genotype).

$a, b$ Least square mean within a row with different superscript differ significantly ( $p$-value). 
otypes. Since the Hardy-Weinberg, principle cannot apply at single genotype situation. Alleles in each line were pooled and considered as one population to calculate the Hardy-Weinberg equilibrium test. Moreover, in pooled population also all the SNPs genotype frequencies were deviate from Hardy-Weinberg equilibrium. The deviation of Hardy-Weinberg equilibrium may be due to the high selection pressure resulting from a 15year program to restore and maintain the five distinct lines of $\mathrm{KNC}$. To date, the chicken population is being maintained as five pure lines.

Since 1994, the Korean government has implemented a project for restoration of KNC. As result, NIAS has established aforementioned five lines of native chicken based economic traits and their plumage colour [11], consisting Black (Heuk-saek Jaerae-jong), Grey (Hoegalsaek Jaerae-jong), Red (Jeokgalsaek Jaerae-jong), Yellow (Hwanggalsaek Jaeraejong), and White (Baeksaek Jaerae-jong) [DAD-IS; http:// dad.fao.org/]. Further, this population were proposed as candidates for selection due to their meat quality and growth differences observed among the lines [12]. These results further supported with high heritability value for body weight traits, moderate heritability values of carcass weight of five lines of KNC [10]. The $M \_2$ and $M \_3$ SNPs described in our study were previously reported by $\mathrm{Nie}$ et al [9]. In his study, these two markers showed significant associations with body weight at 85 days and body weight at 28, 42 days and average daily gain from 0 to 4 weeks, respectively. By comparison, in $\mathrm{KNC}, M \_2$ was associated with body weight at 2 weeks, weight gain from hatch to 2 weeks, and weight gain from 16 to 18 weeks. Additionally, the M_3 SNP marker was significantly associated with weight gain from 14 to 16 weeks and weight gain from 16 to 18 weeks, and with asymptotic body weight. Whereas, no statistical difference at $M \_1$ genotypes was observed for growth traits. Furthermore, not all the other growth traits reported in our study were associated with the SNPs identified here; when compared to the results have been reported by Nie et al [9] and Bhattacharya et al [22] (Supplementary Table S1, S2).

Our results also indicate that the T allele of $M \_2$ is important for high body weights at 2 weeks and for the weight gain from 0 to 2 weeks in this population (TT> CC/CT). These results were similar to those reported by $\mathrm{Nie}$ at al [9]. The $\mathrm{C}$ allele in $M \_3$ was associated with the highest weight gain from 14 to 16 weeks and 16 to 18 weeks and with asymptotic body weight. Further, Jiang et al [6] reported that a POU1F1 polymorphism was associated with chicken growth at 8 weeks of age, and suggested that the SNP (c.299A > T) was effective in early life but that effect was decreased with age. However, in the KNC, the $M \_2$ and $M \_3$ polymorphisms showed a significant association with weight gain at later growth stages and with the asymptotic body weight $(\alpha)$. These findings support the previously described correlation between $\alpha$ and weight gain from 16 to 18 weeks [24]. Our findings indicate that POU1F1 may be one of the genes in group that control weight gain from 16 to 18 weeks and also asymptotic body weight in KNC.

The linkage disequilibrium map of the haplotypes identified in our study shows a higher pairwise correlation value (D') between $M \_2$ and $M \_3$ SNPs (Figure 2). This relationship indicates strong linkage disequilibrium between these two SNPs and, thus, that one of them can easily act as a proxy for the other. However, the correlation between $M \_1$ and $M \_2$, and between $M \_1$ and $M \_3$ was low and, therefore, neither of the other two haplotypes can be used as a proxy for $M_{-} 1$. One main haploid block was identified between $M_{-} 2$ and $M \_3$, therefore, both variants inherent together. The results of the analyses of $\mathrm{D}^{\prime}$ between $M \_2$ and $M \_3$ were further supported by the haplotype and single marker association results.

Overall, our analyses indicate that $P O U 1 F 1$ gene polymorphisms have an effect on the growth of KNCs. $M \_2$ and $M \_3$ in POU1F1 gene were significantly associated with weight gain at late growth period of KNC. T allele of $M \_2$ was responsible for higher body weight at early growth and whereas, $\mathrm{C}$ allele of $M \_3$ was responsible for higher body weight at later growth in KNC. This information will be of value for the improvement of native chicken breeds.

\section{CONFLICT OF INTEREST}

We certify that there is no conflict of interest with any financial organization regarding the material discussed in the manuscript.

\section{ACKNOWLEDGMENTS}

Korea Institute of Planning and Evaluation for Technology in Food, Agriculture, Forestry and Fisheries (IPET) through Golden Seed Project funded by Ministry of Agriculture, Food and Rural Affairs (MAFRA) (213010-05-2-SB250), and "Cooperative Research Program for Agriculture Science \& Technology Development (Project No.PJ012820052018) Rural Development Administration, Republic of Korea was supported for this work.

\section{REFERENCES}

1. Zahra R, Masoud A, Hamid RS, Cyrus A. Identification of a single nucleotide polymorphism of the pituitary-specific transcriptional factor 1 (Pit 1) gene and its association with body composition trait in Iranian commercial broiler line. African J Biotechnol 2011;60:12979-83.

2. Aytekin I, and Boztepe S. Association of Pit1 gene polymorphism with milk yield and composition traits in brown Swiss cattle. J Anim Plnt Sci 2013;23:1281-9.

3. Bodner M, Castrillo JL, Theill LE, et al. The pituitary-specific 
transcription factor GHF-1 is a homeobox- containing protein. Cell 1988;55:505-18.

4. Bona G, Paracchini R, Giordano M, Momigliano-Richiardi P. Genetic defects in GH synthesis and secresion. Eur J Endocrinol 2004;151:S3-9.

5. Tanaka M, Yamamoto I, Ohkubo T, et al. cDNA cloning and developmental alterations in gene expression of the two Pit-1/ GHF-1 transcription factors in the chicken pituitary. Gen Comp Endocrinol 1999;114:441-8.

6. Jiang R, Li J, Qu L, Li H, Yang N. A new single-nucleotide polymorphism in the chicken pituitary-specific transcription factor (POU1F1) gene associated with growth rate. Anim Genet 2004;35:344-6.

7. Mattos de KK, Lama SND, Martinez ML, Freitas AF. Association of $b G H$ and Pit-1 gene variants with milk production traits in dairy Gyr bulls. Pesqui Agropecu Bras 2004;39:147-50.

8. Sun HS, Anderson LL, Yu TP, et al. Neonatal Meishan pigs show POU1F1 genotype effects on plasma GH and PRL concentration. Anim Reprod Sci 2002;69:223-37.

9. Nie Q, Fang M, Xie L, et al. The PIT-1 gene polymorphisms were associated with chicken growth traits. BMC Genetics 2008;9:20.

10. Cahyadi M, Park HB, Seo DW, et al. Genetic parameters for growth-related traits in Korean native chicken. Korean J Poult Sci 2015;42:285-9.

11. Jin S, Park HB, Seo DW, et al. Association of MC1R genotypes with shank color traits in Korean native chicken. Livest Sci 2014;170:1-7.

12. Jung S, Bae YS, Kim HJ, et al. Carnosine, anserine, creatine, and inosine 5 '-monophosphate content in breast and thigh meats from 5 lines of Korean native chickens. Poult Sci 2013; 92:3275-82.

13. Miller SA, Dykes DD, and Polesky HF. A simple salting out procedure for extracting DNA from human nucleated cells. Nucleic Acids Res 1988;16:1215.
14. Falconer DS, Mackay TFC. Introduction to quantitative genetics. 4th ed. London, UK: Benjamin Cummings; 1996.

15. Gonzàlez JR, Armengol L, Solé X, et al. SNPassoc: An R package to perform whole genome association studies. Bioinformatics 2007;23:644-5.

16. Minitab 15 User's guide. Version 15. State College, PA, USA: Minitab. Inc.; 2007.

17. Stephens M, Smith NJ, Donnelly P. Documentation for PHASE. Version 2.1. Seattle, WA, USA: University of Washington; 2004.

18. Barrett JC, Fry B, Maller J, Daly MJ. Haploview: analysis and visualization of LD and haplotype maps. Bioinformatics 2005; 21:263-5.

19. Seo D, Park HB, Choi N, et al. Association of SNPs in AMY1A and $A M Y 2 A$ genes with chicken meat quality and clinicalchemical traits in chicken. J Fac Agric Kyushu Univ 2016;61: 121-5.

20. Hayes BJ. Linkage disequilibrium in livestock populations [Internet]. Toulouse, France: Ben Hayes Course Notes; 2017 [cited2017Jan16]. Available from:http://snp.toulouse.inra. $\mathrm{fr} /$ alegarra/ben_hayes_course/toulouse_course_notes.

21.Xue $\mathrm{K}$, Chen $\mathrm{H}$, Wang $\mathrm{S}$, et al Effect of genetic variations of the POU1F1 gene on growth traits of nanyang cattle. Acta Genetica Sinica 2006;33:901-7.

22. Bhattacharya TK, Chatterjee RN, Priyanka M. Polymorphisms of Pit-1 gene and its association with growth traits in chicken. Poult Sci 2012;91:1057-64.

23. Carrijo SM, Alencar MM, Toral FLB. Association of Pit1 genotypes with growth traits in Canchim cattle. Sci Agric 2008;65: 116-21.

24. Manjula P, Park HB, Seo D, et al. Estimation of heritability and genetic correlation of body weight gain and growth curve parameters in Korean native chicken. Asian-Australas J Anim Sci 2018;31:26-31. 